\title{
Coulisses
}

Revue de théâtre

14 | Printemps 1996

Varia

\section{Débat sur le spectacle}

\section{(2) OpenEdition}

1 Journals

Édition électronique

URL : http://journals.openedition.org/coulisses/4603

DOI : $10.4000 /$ coulisses.4603

ISSN : 2546-9460

\section{Éditeur}

Presses universitaires de Franche-Comté

\section{Édition imprimée}

Date de publication : 1 mai 1996

Pagination : 37-38

ISSN : 1150-594X

\section{Référence électronique}

"Débat sur le spectacle », Coulisses [En ligne], 14 | Printemps 1996, mis en ligne le 20 mars 2019, consulté le 24 septembre 2020. URL : http://journals.openedition.org/coulisses/4603 ; DOI : https:// doi.org/10.4000/coulisses.4603

Ce document a été généré automatiquement le 24 septembre 2020.

Coulisses 


\section{Débat sur le spectacle}

La représentation de L'art exige des sacrifices, applaudie avec enthousiasme, fut suivie d'un débat d'une cinquantaine de minutes entre les spectateurs et la troupe de Saint Pétersbourg (acteurs et metteur en scène Vadim Golikov). La traduction était assurée par Valentine Grosjean et Serge Rolet jouait le rôle de modérateur. Extraits :

\section{Un spectateur :}

J'ai été enthousiasmé par la présence des acteurs et bercé par cette magnifique langue. J'ai aimé cette langue russe.

\section{Le modérateur :}

Vous, spectateurs, avez-vous compris l'enchaînement? Avez-vous tout saisi? Et vous les acteurs, avez-vous effectué des efforts particuliers pour être compris?

\section{Une stagiaire $^{1}$ :}

Quelle qualité de jeu! Quelle justesse! Quelle précision! Combien de temps avezvous mis pour préparer ce spectacle?

\section{Le metteur en scène :}

Toute la journée !... et en gros trois ans. Nous avons un grand répertoire, nous avons déjà travaillé une vingtaine d'extraits de Tchekhov et cette représentation en dénombre huit. En effet, le TU connait un renouvellement constant et même si je travaille depuis trois années sur l'œuvre de Tchekhov, ce n'est jamais avec les mêmes acteurs.

\section{Un spectateur :}

Vous n'avez retenu que les pièces de Tchekhov traitant de l'art, est-ce délibéré?

\section{Le metteur en scène :}

Oui, je m'intéresse à Tchekhov depuis quarante-six ans, mon expérience de cet auteur est donc énorme. Je pense que pour les étudiants du TU, connaître Tchekhov est un grand bonheur. Parmi ses sujets de préoccupation, la question de l'art est privilégiée. Pour la troupe d'étudiants de disciplines diverses, l'enthousiasme pour le théâtre doit déboucher sur quelque chose. Mais montrer une pièce dans son ensemble me semble impossible avec des amateurs. On a voulu exprimer le travail de l'acteur. Avez-vous compris ce message? Comment avez-vous ressenti le spectacle?

\section{Un spectateur :}


La langue est un très gros barrage. J'ai perçu les différences de style dans le jeu chorégraphique mais j'ai eu du mal à suivre le texte. Il y a différentes façons de percevoir le texte. Les moments les plus passionnants sont ceux qui étaient chorégraphiés, presque mimés. L'espèce de fée, de meneur de jeu qui conduisait d'une séquence à l'autre permettait d'obtenir une unité.

\section{Le metteur en scène :}

Le projet du metteur en scène, ce n'est pas de se situer pour ou contre la tradition. Ce n'est pas l'objectif du TU de Saint Pétersbourg. Il s'agit d'évoquer la question de l'art, l'attitude à adopter vis à vis de l'art parce que Tchekhov est quelqu'un qui sait en parler. J'ai eu le projet de lire l'œuvre de Tchekhov intégralement, récits, correspondances, pièces de théâtre, cela m'a pris trois ans. J'ai donc une vision d'ensemble de l'œuvre de cet auteur et ce n'est qu'au cour des répétitions que le fil directeur est apparu. Sur le titre, L'art exige des sacrifices?!, c'est un dialogue avec Tchekhov sur l'utilité de sa propre vie puisqu'il y a consacré quarante années de son existence. En ce qui concernent les jeunes acteurs, les étudiants, ils retiendront de cette expérience le fait d'avoir joué un personnage de Tchekhov. Il y a peu de chance que je monte La mouette en entier. L'intérêt de le monter avec des débutants serait de mettre l'interprétation dans le contexte de la création. La mouette a subi les interprétations des décadents, des nietzchéens, etc.

\section{Les acteurs :}

A travers notre travail d'acteurs, nous avons retrouvé les préoccupations de la pièce. Oui, l'art exige beaucoup de sacrifices! 


\section{Le TU de Saint Pétersbourg}

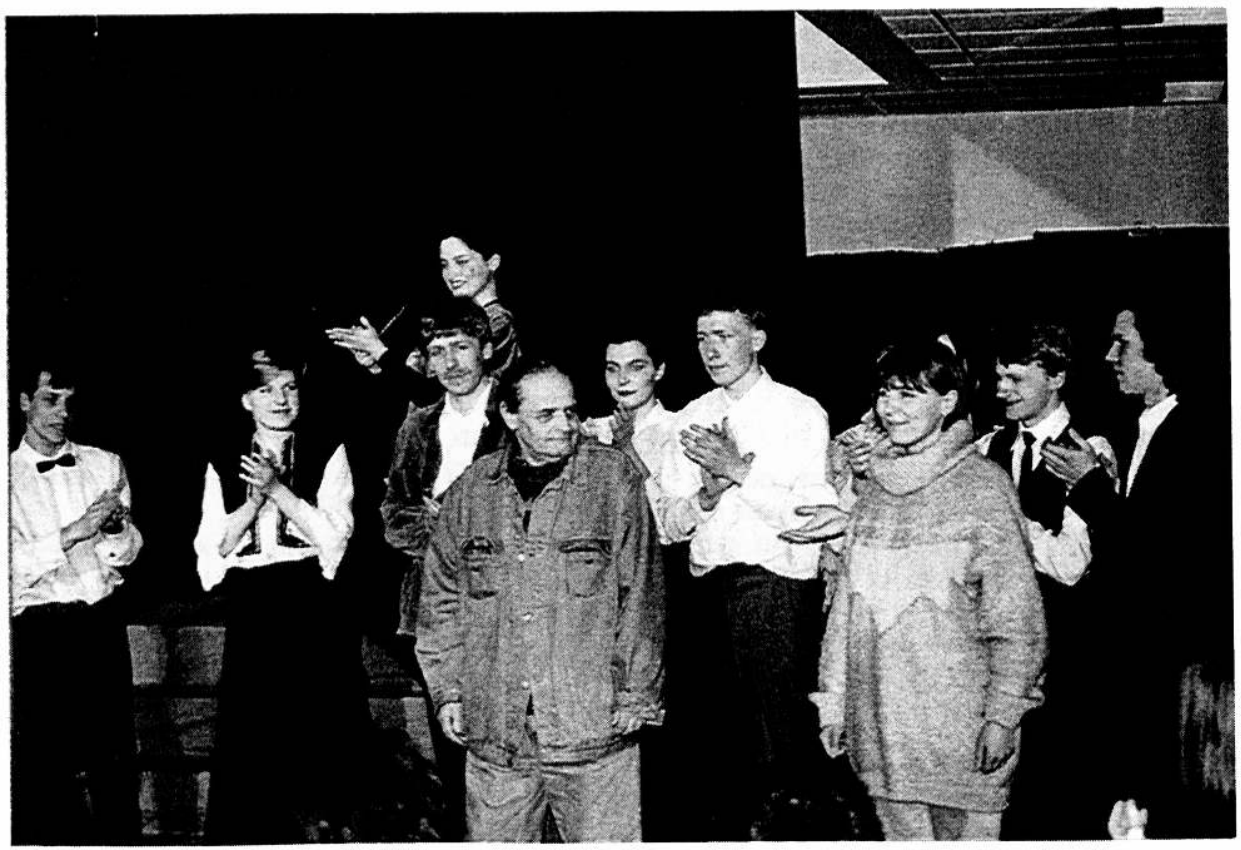

Photo Clément François

NOTES

1. Les $7^{\mathrm{e}}$ Rencontres Internationales Théâtre Université comportaient un stage sur Tchekhov. 